\title{
Impacts of Digital Currency Electronic Payment (DCEP) on China's Banking System
}

\author{
Tong Zhang
}

\author{
China Construction Bank, Henan Branch
}

Email:tongm13@126.com

\begin{abstract}
With the progress of the Internet and big data technology, the format of the currency is transmitting from physical money to digital money. Countries in the world commence to research on the function of the digital currency and Digital Currency Electronic Payment (DCEP) is People Bank of China's practice of the Central Bank Digital Currency (CBDC). While DCEP, bitcoin and third-party payment are digital money, they have differences in several aspects. Central bank and commercial bank play an important role in issuing the DECP. In this article, the influence of the DECP on central bank and commercial bank is explored and we could find that the DCEP could ameliorate the monetary policy and stabilize the financial market, save the cost of using cash and strengthen the financial supervision for the central bank. In addition, for commercial bank, the DCEP could motivate the bank to formulate a new development objective which is more suitable to the Internet financial market.
\end{abstract}

Keywords: DCEP, CBDC, Digital Money, Bank System

\section{INTRODUCTION}

In the economic theory, currency is created to promote the transaction affairs initially and thus is regarded as general equivalent goods. The basic functions of the money are a unit of account, a medium of exchange and a store of value. According to the difference of the issuer, currency could be classified to fiat money which is issued by government and private money issued by private parties. The significant breakthrough in the information technology and the application of the Fintech induces the appearance of a new form of currency which is virtualized and relies on the Internet and the bitcoin is the most famous representative of it. With the development of economic society, the mean of payment gradually becomes the most vital function of currency, and the payment method evolves from cash payment to card payment and now electronic payment arises. Many Internet companies grasp this opportunity and launch their third-party payment Apps, such as Alipay and Paypal.

However, the dramatical progress in the payment and transaction leaves some problems. Since the ultimate goal of the Internet firms is maximizing profit, the third-party payment platforms always charge extra fee from users, and it would accumulate to a great amount of expenditure. Some virtualized currency, especially bitcoin, is not supervised by the government and protected by the law, once decentralized currency encounters a crash, the property security of the owner could not be guaranteed. The People's Bank of China (PBOC) claimed in 2013 that bitcoin was just a virtual commodity, and it is not allowed used by financial institutions in every exchange, clearing and settlement activities. Furthermore, the application of some private money might threat the national monetary policy and financial stability. In addition, a cashless society is the direction of future development, thus it is imperative to launch a centralized digital money that is controlled by the government. Digital Currency Electronic Payment (DCEP) is the Central Bank Digital Currency (CBDC) issued by PBOC, it is digital form of fiat money of the China, with the endorsement of government credit. Utilizing the blockchain technology, DCEP combines the function of digital currency with electronic payment. From April 2020, China government started pilot programs in ten main cities such as Shenzhen and Suzhou [3]. In this process, a two-tier operating system which is central bank and commercial bank is adopted. Therefore, the banking industry has an inseparable 
relationship with the promotion of the DCEP and the implementation of the DECP would generate a considerable impetus on the banking system. The objective of this paper is to analyze the influence of the DECP on the development of The Central Bank of China and commercial bank. Researching on this topic will evaluate banks willingness to popularize the DECP and the government could rely on the results to launch some beneficial policies for banks to promote the DECP. Firstly, the nature of the DECP and its difference with other digital currency will be introduced. Secondly, the influence of DECP on The Central Bank of China and commercial bank will be discussed respectively. Finally, the challenges of launching DECP will be explored and some recommendations will be provided.

\section{THE NATURE OF THE DECP}

\subsection{CBDC and DECP}

Fiat currency is the legal tender which is issued by the government and citizens employ fiat currency as general equivalent goods to carry out transactions with the support of national credit. For a long time, fiat currency exists in a kind of physical version, such as cash and coins, but in recent years a new digital form of fiat currency appears and it is called central bank digital currency (CBDC) [5]. It has the same legal effect as physical money, both as payment instrument and as monetary adjustment tool. CBDC could be realized in two ways: token-based currency and account-based currency. For token-based currency, the central bank issues tokens just as cash but circulate in the market in a digital version. This design will use some form of distributed ledger technology (DLT) to verify payment transactions without the direct involvement of the central bank or other clearing houses. For account-based currency, individuals and companies electronically deposit funds into central bank CBDC accounts or special designated accounts of regulated depository institutions. The transactions are manipulated by the central bank through crediting one account and debiting another [4].

CBDC has three main characteristics. The most essential one is accessibility. As a fiat currency, each individual has the right to hold it and use it to implement every legal economic activity. In addition, High efficiency is brought by the CBDC to the national economy. Since CBDC is digital currency, the time wasted in the traditional transaction to count money is saved and "dual offline payment" also induces the efficiency in the daily transaction settlement. Moreover, the real name regulation is applied in the CBDC. Each transaction is under the supervision of the central bank, thus the government could control the trace of each flow of money easily [7].
Digital Currency Electronic Payment (DCEP) is the practice of the CDBC by China government. In 2014, a legal digital currency research team was established by the POBC, and special research on the issuance framework, main technologies, issuance and circulation environment and related international experience began. At the end of 2017, with the approval of the State Council, the POBC started to organize commercial institutions to jointly implement research and development trials of legal digital currency (hereinafter referred to as digital renminbi, and the letter abbreviation is tentatively designated as "e-CNY" in accordance with international usage practices). In 2020, pilot programs activated in several cities in China. Although cash used in China has significantly decreased in the past years and the aim of the DCEP is replacing the cash in the circulation, the realization of cashless society could not be achieved recently. Therefore, DECP and cash would exist simultaneously for a long time. Though DECP could be applied without the support of Internet, smart device is a requisite for the transaction. However, the possession rate of the smartphone does not reach $100 \%$ in China now. In conclusion, the objective of the DECP is to promote the circulation of the RMB, advance its international influence and improve transaction efficiency and security.

\subsection{The Difference Between DECP and Other Payment Instruments}

The third-party payments such as Alipay and bitcoins are core payment instruments except cash now. Comparing third-party payment with DECP, we could find that DECP is regarded as cash in circulation(M0) and it could not link to bank account but possesses an independent digital wallet. DECP supports both online transaction and offline transaction, NFC technology could be utilized when internet is weak. However, the third-party payment is classified to current deposit(M1) and bank account binding is indispensable. If Internet does not work, the third-party payment would become useless.

Bitcoin is the digital currency that is decentralized and applies cryptographic systems. Decentralization means that all transaction parties use point-to-point transactions, if the central node is attacked, the entire transaction and settlement platform would collapse immediately. On the contrary, The DECP is central bank issued centralized currency, its system is protected and controlled by the government and the security could surely be guaranteed. 


\section{THE INFLUENCE OF THE DECP ON CHINA BANKING SYSTEM}

\subsection{The Structure of China Bank System and Its Relationship with DECP}

Under the current market economy system, banks are increasingly playing the role of the main channel for raising and allocating social funds, becoming the lever for the Chinese government to regulate the macro economy and the hub for adjusting the micro economy operation. The Chinese banking system mainly consists of several parts: The central bank named PBOC, three policy banks, and numerous commercial banks represented by six state-owned entities. Among them, the central bank and commercial banks have a considerable contribution in the implementation of DECP. The target customers of the central bank are government and commercial banks, its duty is issuing currency and adjusting national monetary policy. Commercial bank serves individuals and business for financial affairs. The regulation of the banking system is formulated by central bank, it could allocate funds among commercial banks and government. In some situation, the central bank undertakes the responsibility of bank's bank and provides loans to commercial bank.

The insurance and delivery of the DECP would rely on a two-tier system. For the Upper tier, central bank launches DECP and releases it to commercial banks. For the lower tier, commercial bank distributes the DECP to the public and the final user could make payment through DECP digital wallet [1]. The exchange rate between DECP and RMB is 1:1 and thus the DECP requires commercial banks offer $100 \%$ reserves to PBOC. Reserves means the proportion of fund commercial banks store in the central bank, it is prepared to confront the hostile withdrawn from bank depositors. The $100 \%$ reserve requirement secures the stability of the DECP which is endorsed by sovereignty credit and avoid the risk of a run on the bank.

\subsection{The Effect of DECP on the Central Bank}

The issuance would save the operating cost of the central bank. On the one hand, the traditional physical money should experience a series of procedures before entering circulation: design, print, sorting, transportation and storage, additionally, cash is easily damaged and therefore requires to recycle and print new money continuously. These processes would generate a great sum of cost. On the other hand, DECP promotes direct transactions among digital wallets and the demand for separate clearing and settlement procedure disappears, the cost for former banking clearing and settlement thus eliminates [6].

Central bank is responsible for formulating the national monetary policy and stabilizing the financial market. As the dominant payment instrument created by the central bank, DECP could facilitate the transmission of the monetary policy. Interest-bearing is one characteristic of the DECP, which means it can pay positive, zero or negative interest rate in different states of the economic cycle [4]. Therefore, DCEP is an optimal instrument to stabilize the financial market by moderating the inflation. Furthermore, DCEP could transmit the monetary policy to individuals and companies directly and its competitive advantage compared with private-owned digital money also promotes the monetary policy.

Financial supervision is another duty of the central bank, however, the progress in the Internet threats the security of the financial market especially after the appearance of the crypto-currency. Digital wallet is the software to manage and store DECP. Individuals could employ the digital wallet after registering their phone number with a limitation of the payment. This limitation would be loosened after more personal information is uploaded, in addition, block trading should be operated with the authorization from central bank. "Controllable anonymous" policy is applied on DCEP, it refers to the trading parties with DCEP is anonymous to the public but the central bank could track all transaction information in China. The authentication center, the register center and the big data analysis center are founded by the PBOC to supervise the trading activities through digital wallet. These monitoring methods could eradicate some financial crimes such as money laundering, corruption and tax evasion.

The traditional global payment system: Society for Worldwide Interbank Financial Telecommunication (SWIFT) have controlled the international trading for decades. Applying socialist economic system, China has weak position in this system. With the development of national economic strength and international trading, it is necessary for RMB to improve the influence on the international market. Therefore, the implementation of the DECP could not only protect national economy from the foreign financial attack, but eliminate the reliance on the SWIFT system.

The third-party payment platforms controlled by Internet companies such as Tencent and Alibaba are the major payment instruments in China now. In this circumstance, Internet company could acquire the customer's information easily and use bigdata to provide differential information the customers in order to maximize their profit. Gradually, the Internet companies could manipulate the financial market and might be monopoly in the future, which is a potential threat to the national financial security. Employing the CBDC could catalyze the PBOC to contacts with the customers directly, the personal information and preference would not be revealed to pursue profit and the influence of the third-party payment on the citizens 
would be reduced.

\subsection{The Effect of the DECP on Commercial Bank}

In the traditional commercial bank operating system, cash service relied on ATM machine and real time transfer service relied on POS machine are two of the dominant business in the commercial bank. Since the use of the DECP just demands smartphone and the requirement of physical money declines, POS machine and ATM machine will gradually leave the market. Comparing with the Internet financial company, commercial bank has an advantage that it has a great number of branches in cities, so clients could acquire service face to face. In recent years, the managers of the commercial bank have realized that the offline operational model is out of date and started to explore the digital operational model. Thus, the commercial banks invested a great amount of fund on the electronic transformation of their branches. However, launching the CBDC causes transaction more direct and intelligent, clients could solve every problem online and do not require bank employer's service. In the settlement business, commercial banks would only serve old people who reluctant to use smartphone and those who has bank deposit book. In this situation, commercial bank might reduce the number of branches and the former investment might be wasted. Moreover, the issuance of the DECP requires the commercial bank to exchange digital money to the public, the digital money is not bank binding and would have a negative influence on the bank lending capacity. In order to attract more deposit, commercial bank should rise its interest rate to be more competitive. One the one hand, the higher interest rate increases the funding cost of the commercial bank, on the other hand, the lacking of deposit induces commercial bank to lend money from the central bank and add the funding cost in another way. In order to confront this significant change, commercial bank should adjust their development direction [2]. Commercial bank could utilize the opportunity to be the agent of the DCEP and invest in "new financial infrastructure". In addition, commercial bank could ameliorate Internet finance chain and become a vital constituent of it. Moreover, commercial bank could explore business in other fields, such as sale and marketing.

Furthermore, it is a good chance for commercial bank to avoid to be the subsidiary of the third-party payment platform. In recent years, individuals are willing to create an account in the bank and then link it to the third-party payment platforms. These platforms regulate the money could be transferred from bank account to them freely, but fee should be charged when money is transferred back. When DCEP is populated, individuals could use it from the digital wallet in bank app directly and commercial bank could get rid of the inconvenience brought by third-party payment platform.

\section{CHALLENGES OF ISSUING THE DECP}

Firstly, the research and issuance of the DECP require to invest a great sum of money. The DECP relies on the financial technology such as distributed ledger technology, which might be immature now and thus the system needs constant maintenance. As a new payment instrument, citizens may need a long time to be familiar with it, government would formulate some policies to encourage people to use. For example, some amount of money would be distributed to the digital wallet directly without exchanging with money in bank account Secondly, the European Central Bank released Libra white paper and designed a guideline for the digital euro. As the CBDC report published by Bank of Japan, Japan is well prepared to confront the change brought by CBDC and would issue CBDC soon [8]. While many foreign countries plan to issue $\mathrm{CBDC}$, they are staying at the research phase, which means China has no experience to learn from. This is a new road to world financial market and the probability of failure exists. Thirdly, as we mentioned above, commercial banks play an important role in the issuance, however, the DECP would reduce the lending capacity of the banks. The commercial banks would loss the incentive to distribute the DECP effectively. Finally, the central bank headquarters system is the core of the DECP, nonetheless, it has a probability to be invaded technically and the national financial security would face a significant threat.

Some approaches could be utilized by the government. The interest rate of the DECP could be lower than bank deposit and the central bank could provide some subsidies to commercial bank to rise the interest rate of the time deposit. Moreover, the R\&D department should investigate more to strengthen the technological innovation to ameliorate the network security system.

\section{CONCLUSION}

In summary, this paper discussed the influence of issuing the DCEP on The Central Bank of China and commercial banks, and it could provide references to some government departments to ameliorate the issuing process of the DECP. With the rapid development of the Internet Technology, the benefit of launching a central bank digital currency is obvious. Therefore, PBOC issued China CBDC which is called DECP and started the pilot programs in 2020. Although DCEP, third-party payment and bitcoins are digital money and payment instrument, DCEP is centralized compared with bitcoin and has differences with third-party payment in currency level and service condition. Central bank and 
commercial banks are main financial institutions in issuance procedure. For central bank, the appearance of the DECP could improve the monetary policy and stabilize the financial market. Comparing with the cash, the utilization of the DCEP would reduce the cost of PBOC in circulation and maintenance. In addition, strengthening the financial supervision such as anti-money laundering and international influence of RMB also the benefits of the DCEP. For commercial bank, the traditional operating system would be shocked by the issuance of the DECP. The business related to POS machine and ATM machine might disappear in the future, the lending capacity of the banks would decrease which is a signal for less profit. However, unbinding with the third-party payment might inject new energy to the commercial banks and they would adjust to have a more technical development direction. Confronting with the challenges such as huge investment, no experience to learn from, the lack of incentive from commercial bank and some security problems, several suggestions for the government are also mentioned.

\section{REFERENCES}

[1] Jiang, Z., Sun, Y., Wang, R., 2019. RMB V3.0, China's central bank digital currency: operational framework and technical analysis. Chinese Institute of Digital Assets. Retrieved from https://new.qq.com/omn/20191106/20191106A02U OK00.html

[2] Li, C., Chen, X., Xie, J., and Xiao, J. 2021. Digital Currency, Commercial Banks, Impacts and Outlooks. In 2021 7th International Conference on E-Business and Applications (ICEBA 2021),
February 24, 2021, Sejong, Singapore. ACM, New York, NY, USA, 3 pages. https: //doi.org/10.1145/3457640.3459042

[3] Louie, B. and Wang, M., 2021. China's forthcoming digital currency: implications for foreign companies and financial institutions in China. Journal of Investment Compliance, 22(2), pp.195-200.

[4] Meaning, J., Dyson, B., Barker, J. and Clayton, E., 2018. Broadening Narrow Money: Monetary Policy with a Central Bank Digital Currency. SSRN Electronic Journal,

[5] Wei, S. and Hou, L., 2021. China's Central Bank Digital Currency and Its Impacts on Monetary Policy and Payment Competition: Game Changer or Regulatory Toolkit?. SSRN Electronic Journal,

[6] Xu, J., Prud'homme, D.,2020. China's digital currency revolution and implications for international business strategy[J]. London School of Economics Business Review, Forthcoming, 2020.

[7] Xu, Z. and Tang, C., 2021. Challenges and Opportunities in the Application of China's Central Bank Digital Currency to the Payment and Settle Account System. Financial Forum, 9(4), p.233.

[8] Zou, X. and Cao, Q., 2021. China's National Digital Currency: An Overview of Digital Currency Electronic Payment. Turkish Journal of Computer and Mathematics Education, 12(11), pp.4279-4285. 